\title{
Empowering Children in the Use of Statistics
}

\author{
Susanne P. LAJOIE \\ McGill University \\ VICTORIA R. JACOBS \\ University of Wisconsin-Madison \\ NANCY C. LAVIGNE \\ McGill University
}

\begin{abstract}
Statistics pervade our society, yet the understanding of statistics has remained the domain of a select few. Although the majority of the literature has focused on the adult learner, there is a movement toward teaching statistics to children. This article addresses the ways in which the study of statistics has been examined in the elementary and secondary schools in terms of content, readiness of children to leam, pedagogy, and assessment. A proposal is presented of how a cognitive apprenticeship model can be developed from the empirical research findings in order to build more effective instructional and assessment methods for statistics education.
\end{abstract}

The secret language of statistics, so appealing in a fact-minded culture, is employed to sensationalize, inflate, confuse, and oversimplify. Statistical methods and statistical terms are necessary in reporting the mass data of social and economic trends, business conditions, "opinion" polls, the census. But without writers who use the words with honesty and understanding and readers who know what they mean, the result can only be semantic nonsense. (Huff, 1954, p. 8)

As early as 1954, Huff warned of the dangers of statistical ignorance. Despite the increasing prevalence of statistical information in our everyday lives, the understanding of statistics remains the domain of a select few. This situation is recog-

Preparation of this article was made possible through funding from the Office of Educational Research and Improvement, National Center for Research in Mathematical Sciences Education (NCRMSE). We would like to thank John Lawless for his assistance in accumulating literature for this article and Steve Munsie for his feedback. We also gratefully acknowledge Thomas Romberg, Margaret Powell, and Fae Fredmock for their editorial assistance, and the NCRMSE Statistics Working Group for its help in formulating many of these ideas.

Correspondence and requests for reprints should be sent to Susanne P. Lajoie, Dept. of Educational \& Counselling Psychology, McGill University, 3700 McTavish St., Montreal, Quebec II3A $1 \mathrm{Y} 2$ Canada. 
nized partially in the call for "statistical literacy" (Gal, in press). According to Gal, statistical literacy refers to the ability to interpret statistical arguments in newspapers, news, TV, advertisements, and on-the-job requirements. Statistical literacy goes beyond computational skills and ties to a general movement toward quantitative literacy which is needed when people are constantly bombarded with data to make decisions about their everyday lives (Scheaffer, 1988).

Children are exposed to statistical data as much as adults. Joram, Resnick, and Gabriele (1995) have found that complex data are used for making arguments and claims in both children's and adults' everyday texts (i.e., newspapers, newsletters, and magazines). Children's texts, however, tend to interpret the data for readers less than do adult texts, leaving gaps in the understanding that children must fill in. Both children and adults need opportunities to learn statistics. Considering statistics in the $\mathrm{K}-12$ grades is, however, a relatively new phenomenon. Although the National Council of Teachers of Mathematics (NCTM) provides guidelines for the instruction and assessment of statistics knowledge (NCTM, 1989, 1991, 1995), there is much work to be done to evaluate the success of implementing statistics education in elementary and secondary schools.

In the following article, the NCTM guidelines are reviewed, followed by a discussion of adults' conceptual understanding of statistics. Identifying the misconceptions adults have of statistics can inform educators about the possible needs of students in the $\mathrm{K}-12$ grades. This is followed by a short discussion of some of the developmental considerations for teaching statistics to children, among them whether children's informal knowledge can be used as a foundation for instruction. Finally, exemplars of programs that provide statistics instruction for children in elementary and secondary schools are described, and a possible agenda for future directions in research on statisticcs education for children is suggested. The examples that are presented situate statistics instruction in the context of students' everyday lives, thereby empowering them in the use of statistics. It should be noted that Shaughnessy (1992) provided an excellent review of this area along with a framework for research. We extend his ideas in this article by providing further theoretical connections between cognitive psychology and mathematics instruction as it applies to statistics education along with our own agenda for future research. We do not provide an exhaustive literature review but rather point to areas in the literature that can further the development of effective forms of statistics education and assessment for children.

\section{MATHEMATICS REFORMS IN CURRICULUM AND ASSESSMENT}

Over a decade ago the National Commission on Excellence in Education wrote a landmark report entitled A Nation at Risk (1983). In this report, attention was 
drawn to the declining mathematics scores, and "statistical training" was identified as a target for educational reform. As a response to the need for reform, the mathematics education community suggested that statistics instruction become part of the mathematics curriculum and developed the following documents as guidelines:

- Curriculum and Evaluation Standards for School Mathematics (NCTM), 1989). This publication suggests standards for what concepts students need to learn in the area of statistics and when such education should occur. For example, Standard 10 states that in Grades 5-8, statistics instruction should be situated in real-world examples and include such things as collecting, interpreting, and reasoning about data.

- Professional Standards for Teaching Mathematics (NCTM, 1991). This publication describes how statistical concepts could be taught at specific grade levels.

- Assessment Standards for School Mathematics (1995). This material suggests shifts in assessment toward better ways of assessing student understanding of mathematics, including statistics.

These documents provide reform guidelines for increasing student mathematical power. Mathematical power refers to the ability to formulate and solve problems, make conjectures and formulate arguments, communicate such arguments, and evaluate mathematical claims and evidence. Statistical power consists of the same components but in statistical contexts. The emphasis is on higher order reasoning, problem solving, and communication, as opposed to the recall of factual information. Research is needed to document how students reason with statistics and how best to assess their understanding.

\section{CONCEPTUAL UNDERSTANDING OF STATISTICS AND PROBABILITY}

Statistics has traditionally been reserved for university-level courses, and consequently little information (from research or practice) exists to guide the implementation of NCTM's Standards vis à vis statistics at the elementary and secondary levels. The consensus among educators and researchers is that statistics education, in its current form, is inadequate (American Statistical Association [ASA], 1991; Mosteller, 1988; NCTM, 1989; Posten, 1981; Shaughnessy, 1992). Most individuals have a limited understanding of the subject matter. Given that statistics instruction has generally been restricted to those pursuing professional or academic careers, this is not surprising. What is discouraging, however, is the finding that a large proportion of university students fail to understand elementary statistics concepts (Garfield \& Ahlgren, 1988), even after taking several courses (Posten, 1981). Students' lack of conceptual understand- 
ing is partly due to their having had insufficient early exposure to statistics instruction (Beres, 1988; Posten, 1981; Shaughnessy, 1992).

These findings give credence to the reform recommendation that statistics instruction be included at the precollege levels. Early exposure to statistical information alone, however, may not be enough to empower students. If a large proportion of university students have difficulty with statistical concepts, how can precollege statistics instruction be successful?

An attempt is made below to present a framework for developing statistics instruction at precollege levels based on the literature at hand. First, in an attempt to alert educators to potential learning difficulties in children, a discussion is provided of adult conceptual understanding of statistics and probability. Next, developmental theories are reviewed to ensure that children can learn statistics. Finally, children's intuitions and their informal knowledge are examined within the context of the learning process. Such intuitions may be crucial in informing the instructional design process.

\section{ADULTS' UNDERSTANDING}

\section{Probability and Uncertainty}

The most abundant literature on adults' statistical understanding is in the area of probability. Probability may refer to an attitude of doubt, or degree of belief, with respect to the outcome of some future event (Ferguson, 1971). Probability theory supplies information about the likelihood that the data could have resulted from chance alone (Marascuilo \& Serlin, 1988). Probability theory is used to make decisions about uncertain outcomes. Queries such as "How likely will an event occur: not likely, somewhat likely, likely, equally likely, highly likely" are used to refer to decisions about a future event. For example, How likely is it that I will win the lottery? Or How likely is it that it will rain tomorrow when the weather report states that there is a $70 \%$ chance of rain? Likelihood refers to how certain or uncertain one can be about a future event given the probability of the event occurring.

Shaughnessy (1992) describes three kinds of probability: classical, frequentist, and subjective. Classical probability refers to the assignment of probabilities in an experiment with a random device where all outcomes are equally likely (uniform probability distribution). Frequentist probability assigns probability based on long range behavior of random outcomes. Subjective probability refers to degree of belief. With such diverse definitions there is bound to be confusion in the literature regarding how to teach probability and consequently how to assess student understanding at any grade level. However, as Shaughnessy (1992) points out, there is a growing awareness that students have subjective views of probability and that these notions must be addressed in teaching, rescarch, and curriculum development efforts.

Two widely cited and contrasting examples of research on adults' subjective 
conceptions of probability and uncertainty, the heuristic research (Kahneman \& Tversky, 1973, 1982; Tversky \& Kahneman, 1971, 1983) and the outcome approach (Konold, 1989, 1991; Konold, Pollatsek, Well, Lohmeier, \& Lipson, 1993), are discussed below.

Kahneman and Tversky's Heuristic Research. Kahneman and Tversky have clearly dominated the research on adults' conceptions of probability with their extensive work on judgmental heuristics (Kahneman \& Tversky, 1973, 1982; Tversky \& Kahneman, 1971, 1983). A judgmental heuristic is a strategy that individuals use in the context of everyday reasoning that relies on their informal assessment of a situation. This informal assessment results in an estimation or prediction of a certain event occurring in the future (Tversky \& Kahneman, 1983). Kahneman and Tversky have found that the use of judgmental heuristics can lead to predictable biases, which in some cases are useful and which in others lead to errors in judgment. The interpretation of such errors can serve as a window to the psychological processes that govern judgment and inference under uncertainty (Kahneman \& Tversky, 1982). Perhaps most disconcerting is that such errors are committed by statistically sophisticated respondents almost as often as by statistically naive ones (Tversky \& Kahneman, 1971).

A frequently cited form of the judgmental heuristic is the representativeness heuristic (Tversky \& Kahneman, 1983). The representativeness heuristic is manifested in several ways. First, adults ignore sample size and employ what has been called the law of small numbers (Tversky \& Kahneman, 1971). In other words, adults inappropriately apply the law of large numbers to small numbers. They do not realize that extreme events are more likely to occur in small samples (i.e., small samples are often less representative of populations than are large samples). Second, individuals expect things to balance out, thereby falling prey to a negative recency effect also known as the gambler's fallacy. For example, if one gambler sees another gambler use a slot machine for an extended period of time without success, the first gambler might use that same machine thinking that it will now pay off. In fact, whether the machine pays off or does not pay off remains equally likely, regardless of the outcome of previous trials. Individuals may also fall prey to a positive recency effect-that is, they expect the more recent outcome to "probably" occur. In the slot machine example, the individual predicts that the machine will continue not to pay off (Tversky \& Kahneman, 1971). In making such predictions, individuals ignore fundamental statistical principles, expecting all samples to be equally representative of the population.

Despite their extensive documentation of adults' conceptions of probability, Kahneman and Tversky have been criticized on two accounts. First, their test situations are carefully selected to be counterintuitive. Consequently, their conclusions may be limited to counterintuitive situations, leaving undocumented the performance of individuals in the more common intuitive situations (Hawkins \& Kapadia, 1984). Second, Kahneman and Tversky seldom ask how their subjects 
arrived at solutions, and they only provide the raw percentage estimates of how many subjects fall prey to negative and positive recency effects (Shaughnessy, 1992). Kahneman and Tversky (1982) provide some rebuttal to these criticisms. They claim that they avoid asking subjects to explain solutions because they assume that individuals understand rules often not articulated. Furthermore, they argue that Socratic hints, or other question-answering paradigms, can bias the intuitions the research is trying to study.

Konold's “Outcome" Approach. Konold (1989, 1991) challenges Kahneman and Tversky's probabilistic reasoning approach by suggesting that individuals often use an "outcome approach" that involves nonprobabilistic reasoning to make decisions. According to the outcome approach, individuals do not distinguish between probability and the prediction of the outcome of a single trial. When reasoning under uncertainty, students predicted the outcome of individual trials on a "yes" or "no" basis. For example, when students were asked to interpret a $70 \%$ chance of rain, they did not use the standard probability explanation-that is, given similar atmospheric conditions, it will rain 70 out of 100 times. Rather, students interpreted the question in terms of what the outcome would be and most claimed that it would rain. In general, students felt that probabilities below $50 \%$ indicated no rain, probabilities above $50 \%$ indicated rain, and a $50 \%$ probability meant uncertainty. Konold classified students as to whether or not they used the outcome approach, and in follow-up interviews, he was able to predict the responses of the outcome-oriented individuals to new problems. Konold warns that although the outcome approach is inconsistent with formal probability theories, it is logically consistent and reasonable in terms of everyday decisions. After all, the long-term probability of rain does not tell us whether to carry an umbrella.

Informal Knowledge: Pros and Cons. Kahneman and Tversky and Konold provide contrasting views of the ways in which adults make decisions under uncertainty. The Kahneman and Tversky model suggests that individuals use probabilistic reasoning, but that specific misconceptions interfere with statistical understanding. The Konold model suggests that adults use informal knowledge that is deterministic (i.e., outcome based) rather than probabilistic. Perhaps both models are correct: Adults demonstrate both correct and incorrect reasoning. Konold et al. (1993) found that individuals may switch from one type of reasoning (e.g., probabilistic) to another (e.g., deterministic) while reasoning about situations that would be regarded as similar by an expert. Researchers must select test situations carefully because different situations or problem types elicit different types of reasoning (Horobin \& Acredolo, 1989).

When designing instruction for teaching and assessing students on statistical content about probability, both informal knowledge and possible misconceptions must be taken into consideration. 


\section{CHILDREN'S UNDERSTANDING}

\section{Children's Readiness for Statistics Instruction}

The brief review of adults' understanding of probability has demonstrated that adults have deeprooted intuitions that help or hinder their learning in this area. Such intuitions may develop in childhood. The developmental psychology literature provides a starting point for exploring when and how students can learn statistical content (see Fischbein, 1975; Green, 1983; Piaget \& Inhelder, 1975). Two theories in developmental psychology have been particularly useful in determining children's readiness for statistical instruction, one by Piaget and Inhelder (1975) and the other by Fischbein (1975). Readiness refers to the existing level of learner competency, formal or informal, as a first step in determining how to instruct students. Readiness, as defined in this article, is not strictly linked to age or grade.

Stage Theory and Probability. One of the most influential contributions by developmental psychology to statistics education for children is in the area of probability. Piaget and Inhelder (1975) used clinical interviews to develop a stage theory of the acquisition of probability concepts that is consistent with Piaget's stage theory of cognitive development. In the sensorimotor or preoperational stages (before the child is 7 or 8 years old), children have little understanding of the concept of uncertainty: They are unable to distinguish between certain and possible events. Neither do they understand the concept of irreversibility. Children can only understand irreversible operations by comparison with reversible ones. In the concrete operational stage (at 7 or 8-11 or 12 years of age), children understand the idea of uncertainty by concretely testing ideas in the external world. This testing allows them to distinguish between chance events. Children in this stage, however, are unable to generate a list of all possible outcomes for chance events. In the formal operational stage (when the child is over 11 or 12 years of age), children can think in abstract terms and internally solve problems internally through logic. Children can generate possible outcomes and begin to understand probability in terms of proportions.

Piaget and Inhelder's stage theory was empirically tested with adolescents by Green (1983). He investigated over 3,000 adolescents (ages 11-16) to determine their level of Piagetian development and their understanding of probability. By the age of 16, most adolescents had not reached Piaget and Inhelder's formal operations stage in the acquisition of probability concepts. Green concluded that adolescents have trouble understanding the language of probability (e.g., "at least," "certain," "impossible"). He warned that students often provide "correct answers" without any understanding of the underlying concepts and mathematical processes. He further concluded that extensive, systematic instructional programs are necessary to eliminate this lack of understanding. Horobin and Acredolo (1989) support Green's conclusion that children lack the mathematical 
vocabulary necessary to answer questions dealing with probability. Children in their study were found to confuse possibility with probability. With instruction and corrective feedback, however, such confusion dissipated. Instruction that promotes active involvement of students through discussion can overcome this communication problem (Mosteller, 1980). In a study of middle schooler's statistical reasoning, Jacobs (1993) found that the quality of student written work was far inferior to the reasoning demonstrated in oral exchanges with students. She found that students consistently struggled with written assignments, yet worked effectively in pairs and in small-group, and whole class discussions. Perhaps alternative forms of communication, written and oral, are needed to promote statistical reasoning.

\section{The Use of Intuitions as a Foundation for Instruction}

Fischbein (1975) provides an alternative to the developmental theory of Piaget and Inhelder. IIe disagrees that the acquisition of probability concepts occurs in three rigidly defined stages. Piaget and Inhelder claim that children do not understand the concept of chance before age seven. Fischbein presents evidence that systematic instruction can enable students to acquire the concepts of chance and probability before the Piaget and Inhelder theory states that understanding is possible. His theory centers on the idea of intuitions that can either be beneficial or detrimental in that they can help individuals behave intelligently by simplifying reality, or they can mislead by promoting misconceptions of reality. Fischbein defines primary intuitions as beliefs that are derived from experience without the need for any systematic instruction and secondary intuitions as restructured beliefs resulting from instruction. Primary intuitions could either help or hinder learning from instruction. Piaget and Inhelder claim that children's conceptions of formal operations and chance spontaneously fuse into a probabilistic interpretation during this third level of probability learning. Fischbein argues that these two schemas rarely fuse without systematic instruction-that deterministic and chance interpretations coexist and that individuals often vacillate between the two, reflecting their lack of understanding (see also Konold et al., 1993). Fischein suggests that the intuitive strand of probabilistic thinking is relatively poor and that the formation of secondary probabilistic intuitions is particularly important from the point of view of mathematics curricula.

Fischbein's theory provides strong support for the importance of systematic education in the development of probabilistic intuitions. His criticism of the rigidity of Piaget and Inhelder's probability stages is consistent with other researchers' objections to Piaget's stage theory of cognitive development (for example, see Demetriou, 1987; Levin, 1986; Pinard \& Laurendeau, 1969). Almost since the theory's inception, researchers have been citing counterexamples to Piagct's claim that individual children cannot learn skills, regardless of training, 
until they have mastered the skills from an earlier stage. Furthermore, the problem of horizontal décalage ${ }^{1}$ has continually plagued Piagetian supporters (Case, 1985). However, neo-Piagetians have reinterpreted Piaget's original claims in ways that are better able to account for these empirical discrepancies. ${ }^{2}$ For a neoPiagetian approach to assessing developmental levels of cognitive functioning of statistical and probabilistic concepts in Grades 3-9, see Watson, Collis, and Moritz (1994a, 1994b).

Children intuitions that counter statistical principles may be deeprooted and must be addressed in an educational setting. Schwartz, Goldman, Moore, Zech, Smart, Mayfield-Stewart, Vie, and Barron (1994), for instance, have discovered that fifth and sixth graders have prototheories of fairness that interfere with their understanding of sampling. According to D.L. Schwartz (personal communication, November 13, 1994), prototheories are "initial understandings" that begin to bind a family of resembling situations within a "rule-based understanding." In this way, mathematical and situational generalizations can crystallize. In a sense, a prototheory can serve as a higher order constraint that regulates the assimilation of new relationships. In the case of sampling, children demonstrated the seeds of understanding but their repertoire for applying such understanding was limited to simpler situations. For instance, children studied did not believe in random sampling across grades by pulling names out of a hat because they were afraid that all students selected might be first graders as opposed to being from mixed grades. Jacobs (1993) found a similar result with middle-school children with regard to selecting a random sample of people to ask "Who will win the presidential election?" Students refused to believe that asking a random sample of people was appropriate. Students thought that an equal number of Republicans and Democrats should be asked because that was fair. When the instructor pointed out that there might not be an equal number of Republicans and Democrats in the country, that perhaps there was a 60:40 split, the students still refused to change their sampling method. When a similar sampling question arose for selecting a random sample of $M \& M s$ however, students answered on statistical grounds rather than in terms of "fairness." Both Schwartz et al. (1994) and Jacobs (1993) have found that certain situations resulted in student use of prototypical theories of fairness that interfered with their statistical understanding of sample representativeness. Schwartz suggests that these children may not be able to reason about random sampling fully because they need to consider both the inference from sample to population and the selection of the sample from the population. None-

\footnotetext{
${ }^{1}$ Horizontal décalage refers to the delay, often of several years, between the application of a strategy to one task versus to another in the same stage.

${ }^{2}$ For example, see Case (1985) who claims that each type of thinking leads to a different level of concept or ability-not a qualitatively different type of thinking.
} 
theless, when these situations are isolated children can reason about both of these relationships.

\section{Summary}

The decision making and developmental literature represent both pessimistic and optimistic views regarding the acquisition of statistical understanding. Kahneman and Tversky and Piaget and Inhelder are somewhat pessimistic in terms of when and how students can learn statistics. Kahneman and Tversky (1973) point to adults' statistical misconceptions and argue that instruction cannot remedy such problems. Piaget and Inhelder (1975) propose that students cannot reason about statistics until they have acquired the capacity for formal operations. On the other hand, Konold (1989, 1991) and Fischbein (1975) reason that students have statistical skills in place and ready irrespective of their age or grade. Horobin and Acredolo (1989), Schwartz et al. (1994), and Jacobs (1993) each have found evidence that students had informal knowledge and intuitions that could be brought into a formal educational setting to deal with statistical problems. Some intuitions and prototheories, such as fairness versus representativeness and possibility versus probability, are difficult to change. However, Horobin and Acredolo have found that corrective feedback can facilitate children's understanding of statistical concepts. Students need problem-based or activity-based learning environments that will support such understanding (Fong, Krantz, \& Nisbett, 1986; Jacobs, 1993; Schwartz et al., 1994). The work of these latter scholars leads us to suggest that statistics instruction can build on children's informal knowledge in the $\mathrm{K}-12$ grades.

The existing research supports two conclusions: (a) instructional interventions do improve the frequency and quality of statistical reasoning and (b) instruction needs to be activity based to allow students to confront their misconceptions directly (Fischbein \& Gazit, 1984; Fong et al., 1986; Jacobs, 1993; Kapadia, 1983; Schwartz et al., 1994; Shaughnessy, 1992). Tversky and Kahneman (1971) have shown that some misconceptions do persist even after statistics training. However, the positive influence of statistics instruction provides hope for educators. Research suggests that this improvement might be even more dramatic if statistics instruction emphasized ways to use statistical principles in everyday life rather than in standard, contrived statistical examples (Fong et al., 1986; Mosteller, 1980; Nisbett, Krantz, Jepson, \& Kunda, 1983).

Research on statistics education carries a heavy emphasis on misconceptions in probability and less emphasis on how students reason about chance, randomness, the law of large numbers, central tendency, means, variance, and distributions (Garfield \& Ahlgren, 1988). Vast areas of statistical understanding still need to be addressed. The next section provides some exemplars of activitybased statistics instruction for children. This is not an exhaustive list of all the programs that teach children about statistics but rather a brief look at some programs. 


\section{EXEMPLARS OF HOW TO EMPOWER CHILDREN IN THE USE OF STATISTICS}

Some lessons learned from mathematics education research can be applied to statistics education research. School mathematics has traditionally been accepted as a well-structured discipline where answers are either right or wrong (Resnick, 1989). The same could be said generally of statistics instruction. The final product is often of primary importance; the processes leading to a particular answer, secondary. Students are not always given opportunities to illustrate and explain their reasoning when solving a mathematics or statistics problem. They are asked to memorize facts and procedures (Bransford et al., 1989) rather than to use their problem-solving capability. Learners consequently fail to understand concepts and do not apply acquired knowledge to other areas. Learning abstract concepts in this context is difficult, discouraging, and meaningless unless instructional approaches make the concepts less ambiguous and more concrete.

Treating statistics as an ill-structured discipline, where there is more than one right answer, can open the doors to alternative forms of teaching and learning that emphasize the constructive, active nature of learning rather the traditional receptive view. Alternative teaching methods that utilize a problem-solving approach to teaching statistics at the elementary and secondary schools can reinforce the active nature of learning. Such methods can be closely tied with the appropriate statistical content for specific grade levels. Furthermore, such methods may include opportunities that enable students to be active learners, empower students, are engaging, provide students with opportunities for doing statistics, and demonstrate relevance to real-world applications (Garfield \& Ahlgren, 1994; Lajoie, Lawless, Lavigne, \& Munsie, 1993; Scheaffer, 1988, 1990; van Reeuwijk, 1992). Doing statistics involves opportunities to inquire, investigate, analyze, and interpret rather than to compute and memorize. Such active involvement makes statistical terms more meaningful, facilitates understanding, and demonstrates the use of statistics in analyzing real-world problems (Fischbein \& Gazit, 1984; Kapadia, 1982; Pereira-Mendoza \& Swift, 1981; Shaughnessy, 1983, 1992; Singer \& Willett, 1990; Tanner, 1985; Varga, 1983; Watts, 1991). The situated learning framework supports the learning-by-doing philosophy by suggesting that statistical concepts are less abstract if individuals interact directly with objects and materials in the learning situation rather than manipulate abstract symbols which are detached from their referent (Greeno, 1989).

Several researchers discuss the advantages of "doing statistics" using technology for teaching precollege statistics (de Lange, Burrill, Romberg, \& van Recuwijk, 1993; Hancock, Kaput, \& Goldsmith, 1992; Lajoie, Lavigne, \& Lawless, 1993; Lajoie et al., 1993; Lehrer \& Romberg, in press; Rosebery \& Rubin, 1989; Russell \& Friel, 1989; Scheaffer, 1988, 1990; Schwartz et al., 1994). Some of these studies in statistics at the elementary and secondary school levels are 
reviewed in the sections below. These studies have different strengths, ranging from large scale curriculum efforts, such as the Quantitative Literacy project (QLP), to fine grain studies that focus on student reasoning, such as that presented by Lehrer and Romberg (in press). These exemplars represent the diversity in viewpoints for examining statistics instruction; that is, those by mathematics educators and psychologists. Such viewpoints are described in Shaughnessy's (1992) review.

\section{Quantitative Literacy Project}

The QLP presents an innovative approach to teaching statistics and probability in the $\mathrm{K}-12$ grades, along with guidelines for teacher training and the use of curriculum and assessment materials. The QLP materials include exploring data, probability, the art and techniques of simulation, and surveys and information from samples. The QLP was developed in collaboration with the ASA and NCTM joint committee on statistics and probability (see Scheaffer, 1988 for a full description of this project). All the data sets are real and provide students with hands-on experience. The QLP has been in place for several years, and two of the units, exploring data and exploring probability, have been evaluated by two independent parties (Day, Webb, Nabate, \& Romberg, 1987; Garfield \& Ahlgren, 1994).

Garfield and Ahlgren (1994) conducted a survey of student responses (Grades 6-12) to the QLP units. Students were asked how well they believed they understood the content and whether they liked studying topics in probability and statistics. Results indicated that student perceptions of understanding the material were higher than their reports of liking the material. Students in the higher grades (Grade 12 vs. Grade 9) reported liking the materials more than younger students. Garfield and Ahlgren's (1994) evaluation of student interest in the QLP is an important one. However, their evaluation of the QLP was based strictly on student perceptions rather than on student performance. Garfield and Ahlgren do not address how well students learn the probahility and statistics materials presented in the QLP. The relationship between student interest and student learning needs to be clarified in determining the success of the QLP.

The Day et al. (1987) evaluation of the QLP materials goes beyond the Garfield and Ahlgren study by examining both student interest in and learning of statistical concepts presented in the Exploring Data and Exploring Probability units. A quasi-experimental design was used to compare experimental (QLP students) and control group (regular students) learning on pre and posttests of statistics and probability. QLP students scored higher than the control group on posttests of statistics and probability, especially on items that required knowledge of (a) computing probabilities when data are given numerically, (b) particular techniques for designing data (i.e., stem and leaf plots, box plots, and line plots), and (c) the concept "outlier." The QLP materials were not more effective than regular coursework in teaching some of the more routine skills of reading graphs 
and computing probability using a tree diagram. About a third of the teachers in the experimental groups stated that the amount of time they devoted to the QLP materials was dependent on knowing that the students would be evaluated on the materials. This statement supports Frederiksen and Collins (1989) assertion that teachers teach to the test: Time on task or what gets taught seems related to what gets tested. In terms of student interest, students in QLP groups reported liking mathematics more and felt they had more understanding of mathematics but planned to take less mathematics than students in the control group.

One connection can be drawn between the Garfield and Ahlgren and the Day et al. evaluations. In the former study, students in the higher grades, 9-12, reported liking the QLP materials more than students in the earlier grades. In the latter study, teachers thought the QLP materials were most appropriate for Grades 9 and 10. The relationship between student interest and teacher beliefs about the materials has implications for developing appropriate statistical content for specific grade levels. Teacher workshops can emphasize this relationship and make statistics instruction more meaningful. Workshops are especially important because teachers sometimes find teaching new content, or teaching in a new manner, difficult (van Reeuwijk, 1992).

The QLP, presents an example of how statistics instructional materials can be implemented effectively at the elementary and secondary grades. The effective implementation rests on proper teacher workshops on how to use the materials as well as systematic evaluations of whether students are learning from these materials. QLP is a large scale curriculum project. Lehrer and Romberg (in press) provide an analysis of student thinking in the context of developing a model of specific data.

\section{Statistics for Fifth Graders: Data Modeling}

Lehrer and Romberg (in press) strongly emphasize the importance of models in statistical thinking. They define a statistical model as the process in which one induces or deduces patterns from the data. Because they are interested in promoting statistical reasoning that is model based, they chose to use Tabletop (Hancock et al., 1992), a computer tool for exploring data modeling. According to Hancock et al., data modeling equals data creation plus data analysis. Simply put, before one can analyze data, one must create or collect data. By creation of data, Hancock et al. refer to the process of planning the collection process based on the expected data analysis. Data processes concern the collection, organization, and structuring of data so that appropriate data analyses can be performed.

Lehrer and Romberg (in press) support Hancock et al.'s (1992) definition of data modeling and have implemented a project-based learning environment, using Tabletop, in a Grade 5 classroom. Using a combination of technology and project-based learning, Lehrer and Romberg hoped to improve statistical reasoning by situating learning experiences in student-generated tasks. Students formed data teams, through which they generated research questions with the assistance 
of researchers who served as teacher-facilitators. Lehrer and Romberg found Tabletop to be an effective computer tool for modeling data because it emphasizes a variety of data types (i.e., categorical and numeric), as well as multiple visual representations for each data set. For example, students can choose to view the results of their research question by plotting a Venn diagram, or by plotting their data as dimensions on a graph with common axes. Furthermore, each datapoint that a group collects, whether 20 subjects, or 20 breeds of dogs, can be visually represented by an icon that reflects that datapoint. Representing individual datapoints visually helps students reason about patterns and predictions.

Lehrer and Romberg concluded that students need to construct data before they can fully understand data analysis. They found that students in their study did not initially have the ability to develop questions, treat data as objects, or identify, organize, and code different types of data. Through instructional experiences with data construction, however, students were able to master these skills. Students struggled with issues such as the need for uniform codes, the identification of superordinate categories of data, and the use of their tacit world knowledge to make judgment calls about ambiguous data. While studying the datateams' verbal protocols, Lehrer and Romberg made an interesting observation about how students reason about research questions. Lehrer and Romberg suggest that a "conversational metaphor" can be used to describe student thinking about data. The students in the study conceptualized "questioning" as solely conversational. They initially resisted the idea that they could ask questions of data (as opposed of people). Through instruction, however, students effectively learned to treat data as objects that could be questioned. Furthermore, after developing this understanding, students were able to reason about data that included one or more variables, and they were able to discuss which representation would be more effective in demonstrating their findings. It appears that 5thgrade students can reason about statistics in a complex manner and that, once again, their informal knowledge is a critical determinant of how well they understand instruction in this area.

\section{The Used Numbers Project}

The Used Numbers Project (UNP) (Russell \& Friel, 1989) is another example of statistics instruction for elementary school students. The UNP involves the "real use" of numbers, such as the way data are used in tables, graphs, and diagrams. Real data, as Russell and Friel define it, are messy, in that decisions must be made that require the weighing of constraints in collecting, organizing, representing, and analyzing data. The UNP consists of instructional modules that make use of computers and calculators as mathematical tools for characterizing the overall shape of the data, summarizing the data, and interpreting the data. Russell and Fricl have devcloped a set of questions that probe students about their theory development as it pertains to how they interpret data. These questions, if 
internalized by students, can lead to critical attitudes toward the statistical process. For instance, Do the data make sense? Are the data appropriate to the intended use? Do the data tell me what I want to know? Can I represent the data differently and get a different answer? Students learn what questions are important to ask of their data, how to conjecture, how to identify relationships in the data, how to withhold judgment until the information is in hand, and how to build theories based on the data they collect. As discussed earlier, this process of questioning the data can be described as a "conversational metaphor" (Lehrer \& Romberg, in press) whereby children learn that the data can be questioned.

\section{Statistical Problem Solving for Eighth Graders: Authentic Statistics}

Statistics instruction using technology, as demonstrated by the Tabletop software and the UNP, can be successful in elementary school. The Authentic Statistics Project (ASP) extends this approach to the middle school, Grade 8, and examines the relationship between instruction and assessment. The ASP is a computerbased environment for teaching and assessing eighth graders' statistical problem solving (Lajoie, Lawless, Lavigne, \& Munsie, 1993; Lavigne, 1994). Students are "authentically" instructed and assessed. Authentic in this case refers to statistical activities that are of relevance to the students who participate in the project. Students ask research questions that are of interest to them and subsequently collect and analyze data that will answer their questions. By authentic assessment the researchers state that assessment activity is intertwined with instruction so that one informs the other. It can be argued that students cannot be authentically assessed unless they understand the criteria on which they will be assessed. One of the primary goals of the ASP has been to make assessment goals open to the learners. This goal is described in the library of exemplars study (Lavigne, 1994).

\section{Library of Exemplars Study}

The purpose of the library of exemplars study was to make the statistical assessment clear to the learner through the use of computers. Students work together in small groups to design a research question and to collect their own data. The computer is used to represent their data graphically, to analyze their data statistically, and to demonstrate their interpretations to the class. Two computer conditions were developed, video and text, to demonstrate exemplary performance on the statistics criteria in question. The assumption was that when students are made aware of what is expected of them, it is easier for them to meet those expectations. Technology can be used to make such expectations clearer. The difference between the two conditions was that the video condition presented computerized video segments of student performance on these criteria, whereas the text version described the criteria only in prose. The exemplars were constructed by selecting videotapes of past students who demonstrated weaker and stronger performance on the above statistical components. These tapes were then digitized and used in the library of exemplars so that students could use these 
examples to study how other students solved similar problems, and to identify acceptable performance on each criterion.

Students in both conditions demonstrated significant overall gains in statistical knowledge from pre to posttest for the following statistical concepts: population, sample, sampling, sample size, mean, outlier, range, and graph interpretation, but not for median and mode. No significant differences were found between the text and library conditions. Perhaps the gains in each condition, and the lack of difference between conditions, could be due to the fact that making assessment criteria clear, in any fashion, improves performance.

The ASP was geared toward teaching students descriptive statistics in an authentic manner. The results were positive as demonstrated by the pre-posttest gains in statistical knowledge. The computer environments were found to motivate as well as to assist students in efficient management and interpretation of data. Students had difficulty, however, calculating the mean, median, and mode by hand. This finding may be due to the instructional emphasis on interpretation rather than on computation. More research is needed to determine if there is a natural progression for instruction. Some believe that providing students with early experiences in "doing" statistics will promote higher order reasoning skills, such as data interpretation. Technology can be used to compute the statistics for the students, facilitating higher order skills and allowing students to reason with the data more readily. Others believe that higher order reasoning cannot precede the prerequisite understanding of basic statistical concepts. Perhaps as Scheaffer (1988) noted, students should not go to the computers too quickly, but rather first experience hands-on work dealing with basic concepts. These are questions that need empirical answers prior to curriculum change in statistics education for elementary- and middle-school children.

\section{Developing Statistical Reasoning in High-School Students}

A computer-enhanced curriculum for high-school students that emphasizes reasoning and learning-by-doing has been developed to help students learn the hows and whys of statistics through real-world problems (Rosebery \& Rubin, 1989). The reasoning under uncertainty (RUU) curriculum uses computer software that provides an environment for learning abstract statistical thinking (ELASTICTM) (Rosebery \& Rubin, 1989). The statistical content focuses on variability in distributions, methods of asking and answering statistical questions, and the interplay of probability and decision making. The use of interactive graphics in high-school for teaching statistical content is unique. ELASTIC supports statistical reasoning through the following features: (a) stretchy histograms, that allow for the manipulation of a distributions shape; (b) sampler, a laboratory for running experiments where students can take repeated samples and compare distributions and growth of means and medians; and (c) shifty lines, an interactive scatterplot that allows for expcrimentation with line fitting through data points. Included in the curriculum is a paper-and-pencil activity called Distribution 
Teasers, which stimulates student reasoning about how variables represented in a graph relate to each other and what a graph reveals about the population.

Rosebery and Rubin report on the use of the RUU curriculum and ELASTIC software at three high schools. Teachers stated that the students who took part in the study were motivated by the curriculum, learned to interpret rather than compute statistics, and understood the statistical procedures rather than simply the computations. Teachers reported that these activities helped students understand that statistics is a sense-making activity, and students learned to stop to think about their data. Rosebery and Rubin discuss the success of their project in terms of teacher testimonials as to whether or not the curriculum was successful in promoting reasoning in the classroom. As van Reeuwijk (1992) pointed out, teacher acceptance of new curriculum materials is the key to successful implementation of that curriculum. In addition to teacher acceptance, evidence of student learning is crucial in determining the effectiveness of new curriculum materials.

\section{Summary}

The QLP, Lehrer and Romberg's use of Tabletop for data modeling, UNP, ASP, and RUU, described above, all use technology for data representation. Students can make changes to their representations quickly and see their results instantly. Students learn to communicate with graphs and quickly learn that different graphs are better for different kinds of data. Technology can help students test their hypotheses about data, by providing multiple experiences with graphs and by facilitating the reasoning about the connections between graph construction and representation and meaning of data. Scheaffer (1990) reiterates that the computer is a strong tool for teaching exploratory data analysis, or model building, because it is graphical in nature and can demonstrate the complete scientific investigation process. He cautions, however, against using technology for data analysis prior to student understanding of basic statistical concepts. This caution was reaffirmed by Lavigne (1994).

Another related question pertains to the ease with which children can use technology to answer statistical questions. In each of the preceding studies, students were provided with technology to solve statistical problems. Each study may have had its own limitations, however, in terms of the ease with which students could manipulate such tools. Hancock et al. (1992) eloquently described the relationship of data organization to data creation. When students are asked to design research questions and collect the data to answer their questions, they often have difficulty with data organization. Lavigne (1994) found that students frequently revised their research questions after they had collected and entered their data into the computer. For example, when collecting survey data, students frequently asked all available subjects and entered each subject into the computer as a separate data point. Later these students revised their question to ask whether boys and girls differed in their responses to the survey. Students were prevented, 
however, from performing a data analysis because they did not understand how to collect and organize the data for the given data analysis. When designing statistical instruction using technology, developers might address the data organization task as a key aspect of instruction. Students need to be explicitly taught the relationship between data organization and data analysis.

Although it is difficult to compare the above studies because of the variation in statistical content and grade level, the conclusion appears positive that statistics can be taught to and understood by children in the $\mathrm{K}-12$ grades. Activitybased approaches, in a small-group context, appear to empower students in the use of statistics.

\section{PRESCRIPTIONS FOR FUTURE DIRECTIONS}

The following discussion points to certain target areas for future research in the area of precollege statistics that can help build a more integrated model for the instructional and assessment process. This model includes looking at what statistical content to teach, when and how to teach specific statistical content, and how to assess student understanding of statistics. The cognitive apprenticeship model is proposed as one possible means for developing this conceptual framework for future research. This model is described below.

\section{A Cognitive Apprenticeship Model for Teaching and Assessing Statistics}

A possible agenda for future research in statistics pedagogy may be to look toward the successful approach described by Collins, Brown, and Newman (1989). They describe a cognitive apprenticeship approach to instruction that is designed around the notion that skilled learners can share their knowledge with less skilled learners in order to accomplish cognitive tasks. Learners see other learners at various stages of development, which encourages them to see learning as an incrementally staged process, while providing benchmarks for their own progress. Cognitive research, through such methods as protocol analysis, has begun to delineate the cognitive and metacognitive processes that have embodied the tacit knowledge of experts. Making this tacit knowledge explicit is a first step in enhancing instruction by allowing students to observe, acquire, and practice such skills. Collins et al. cite Schoenfeld's (1985) research as an example of the use of cognitive apprenticeship as it applies to mathematical problem solving. What still needs to be developed is a cognitive apprenticeship model for teaching statistics.

A cognitive apprenticeship approach to teaching statistics would need to address appropriate content, sequence, sociology and method.

\section{Content and Sequence of Statistics Instruction}

Statistical content and learner conceptual understanding of that content needs to be investigated concurrently. The short review of the developmental literature 
provided in this article suggests when students are ready to learn statistics. There is some consensus that informal knowledge is quite strong in the early grade levels and can be used to guide statistics instruction. At the moment there are only a few studies that provide the cognitive research that documents the ways in which this informal knowledge can be used to guide instruction (Fischbein, 1975; Fong et al., 1986; Green, 1983; Hancock et al., 1992; Horobin \& Acredolo, 1989; Jacobs, 1993; Konold, 1989, 1991; Konold et al., 1993; Lehrer \& Romberg, in press; Schwartz et al., 1994; Shaughnessy, 1992).

A concerted effort to identify what statistical content students are expected to acquire at different grade levels would help build a connected curriculum through Grades $\mathrm{K}-12$. There is an abundance of literature on probability compared to that on inferential statistics (Garfield \& Alghren, 1988). Some researchers have examined both statistical content and sequence in an attempt to determine what would be appropriate in order to make best use of student prior knowledge (Beres, 1988; Scheaffer, 1988). Scheaffer, for instance, stated that students should learn exploratory data analysis prior to confirmatory analysis. Although there is a great deal of discussion about data representation, there is less information available about the relationship between data organization and data analysis (Hancock et al., 1992; Lavigne, 1994). Examining this relationship as it pertains to instruction would be useful. There is a need for research regarding statistical content and how and when that content should be taught in $\mathrm{K}-12$ grades. Further examination of statistical reasoning, problem solving, and communication across the curriculum is also needed.

\section{Sociology}

The cognitive apprenticeship model goes beyond content and sequencing and addresses the sociology of the classroom in its model of instruction and assessment. The research reviewed in this article indicates that statistics can be taught to students in all grade levels given the appropriate contexts. The sociology of the classroom can provide the needed context to learn statistics. Research has shown that the use of small-group problem-solving activities that involve realworld situations are most productive for promoting the learning of statistics. This statement, however, should not be overinterpreted. There is a large body of literature on small-group learning that should be reviewed by those interested in using this approach in the statistics classroom. For instance, social interactions can promote thinking and the development of problem-solving skills by exposing individuals to multiple points of view (Vygotsky, 1978). Attention needs to be paid, however, to the dynamics of small-group interactions and to the ways such collaborations affect learning (Webb, 1991). Although peer collaboration can result in shifting perspectives, the mere presence of peers is not sufficient for effective learning; joint decision making is necessary (Rogoff, 1991). Group work can result in a reliance on others that may reduce personal responsibility and independent thinking (Blumenfeld et al., 1991; Corno \& Mandinach, 1983). Relating statistical content to prior knowledge, misconceptions, and to real- 
world situations has been found to increase statistical understanding (as discussed above), but more extensive analyses are needed to understand such complex relationships across statistical content in small group contexts.

\section{Methods for Statistics Instruction}

Can teaching methods be designed to help students acquire and integrate cognitive and metacognitive strategies for using, managing, and discovering expert strategies in statistical contexts? The cognitive apprenticeship model includes six methods for developing an optimal learning environment: modeling, coaching, fading, articulation, reflection, and exploration. Modeling, coaching, and fading all refer to helping students acquire knowledge in the context of the problemsolving situation. Expert skills are modeled, and students are coached through hints on what to do next. As students become proficient, coaching is faded. Articulation and reflection are methods designed to help students gain conscious access to and control of their own problem-solving process. Articulation methods include activities whercby students become their own critics by learning to summarize, clarify, and question themselves. Articulation can be encouraged in the classroom by providing students with the appropriate statistical vocabulary for engaging in statistical discourse. Reflection methods enable students to compare their processes with an expert and can be supported by teaching students to critique their own work and that of others. Exploration is a final method aimed at establishing learner autonomy in carrying out expert problem-solving processes and in defining or formulating problems to be solved. Exploration can be encouraged through self-generated research questions and the use of technology and project-based activities.

These six methods must be considered in the context of appropriate sequencing of instruction which takes different skill levels of acquisition into consideration. Furthermore, the sociology of the learning environment must be considered in terms of the community of learners present in the classroom. Students can learn both from working with more capable peers and by teaching less capable ones.

In reviewing the research, "doing" statistics could be better taught if communication and critiquing skills were modeled for the learner in the context of problem-solving activities. Problem-solving skills must also be modeled and they include such components as problem generation, problem representation, data creation, collection, organization, analysis, and interpretation.

Modeling Communication and Critiquing Skills. One of the major NCTM reform messages is that students must be given opportunities to communicate how they reached an answer. Often this communication must be verbal rather than written. Verbalizations may be more useful than written text for certain age groups and may, in fact, lead to richer articulations of what students know or do not know. Jacobs (1993) supports this finding in her research on middle school- 
ers' understanding of statistics and probability. She found that the quality of student written work was inferior to the reasoning demonstrated in oral exchanges. Verbalizations were also the core of data leading to Lehrer and Romberg's (in press) identification of the conversational metaphor guiding student reasoning about data. Russell and Friel (1989) developed a systematic set of probes to facilitate children's communication about statistics. Children can learn to communicate their statistical understanding by providing them with a vocabulary with which to discuss their ideas (Carpenter, Fennema, Peterson, Chiang, \& Loef, 1989; Lampert, 1986; Resnick, 1989). Appropriate methods can be developed to code and assess student dialogues about statistics.

One of the ways communication skills can be formally studied in the context of statistical reasoning is through the use of "critiquing." Critiquing in this context refers to the ability to articulate the reasoning behind one's own inferences or those of others. Statistical reasoning is best examined in the context of complex problems.

Critiquing statistical work is an essential skill that should be both developed and assessed. As consumers of statistics, students must learn to read and evaluate the statistics they encounter in newspapers, in magazines, and on TV (see Gal, in press; Joram et al., 1995). In addition to being able to read statistics, learners must be able to determine whether the statistics are to be trusted. For instance, do students question material they read, such as " 4 out of 5 experts say that a Brand $\mathrm{X}$ prevents tooth decay?" Do students ask themselves how the data were collected? Perhaps 100 different experts were asked until 4 experts in a row said the product prevented tooth decay. The point is that students must learn to be savvy about statistics and be able to question how representative the data are. It is essential that students be taught to critique statistical methodology and statistical interpretations in order to make them more reflective about what they read and possibly assist them in making everyday decisions.

Modeling Statistical Problem Solving. There are several statistical problemsolving components that can be considered in modeling statistical competence. As with other problem-solving tasks, the way students represent the problem can determine how well they solve it. A major portion of problem representation rests with the ability to understand the problem statement. For example, how do students interpret statistical vocabulary? Words that reflect "probability" to a statistician may simply reflect "outcomes" to students (Konold, 1989, 1991).

Another major part of the task may be formulating the research question and following through with data creation, collection, and interpretation. Lavigne (1994) suggests providing exemplars of the statistical problem-solving process in order to assist the novice learner. Because assessment criteria were made explicit in the library of exemplars, students understood what was expected of them, as demonstrated by their performance. Lehrer and Romberg (in press) and Hancock et al. (1992) pay particular attention to the data-creation phase of problem solv- 
ing, concentrating on the process of planning the data collection in order to prepare for the expected data analysis. Special attention must also be paid to how data are represented once they are collected. For instance, do students understand how to organize data in a manner that allows them to conduct the appropriate data analysis for their research question? Selecting the appropriate type of analysis and designing a study to support this analysis are major components of statistical problem solving.

Further empirical work may highlight other components of statistical proficiency that should be modeled, coached, and then faded once learners have acquired such knowledge. As research grows in the area of statistics instruction and assessment for precollege students, we will need to build a "model" of what statistical competence means in the context of different content areas. With such a model in place, the quality of instruction and assessment for students at different levels of learning can be improved. In order for the model to be effectively implemented in the classroom, preservice teachers would need to be sensitized to students' statistical misconceptions and beliefs (Shaughnessy, 1992). Collaboration between teachers and researchers is essential for improving learning in classrooms. As Shaughnessy (1992) recommends, teaching experiments that are designed to examine the effects of instruction need to be designed where researcher-teacher collaboration is in-place. It is only then that the effects of instructional change can be objectively documented and truly implemented in the classroom.

\section{REFERENCES}

American Statistical Association (1991). Guidelines for the teaching of statistics $K-12$ mathematics curriculum. Landover, MD: Corporate Press.

Beres, Richard J. (1988). Statistics for college-bound students: Are the secondary schools responding? School Science and Mathematics, 88(3), 200-209.

Blumenfeld, Phyllis C., Soloway, Elliot, Marx, Ronald W., Krajcik, Joseph S., Guzdial, Mark, \& Palincsar, Annemarie (1991). Motivating project-based learning: Sustaining the doing, supponting the learning. Educutional Psychologist, $26(3$ \& 4), 369-398.

Bransford, John, Hasselbring, Ted, Barron, Brigid, Kulewicz, Stan, Littlefield, Joan, \& Goin, Laura (1989). Uses of macro-contexts to facilitate mathematical thinking. In R.I. Charles \& E.A. Silver (Eds.), The teaching and assessing of mathematical problem solving (pp. 125-147). Reston, VA: National Council of Teachers of Mathematics.

Carpenter, Thomas P., Fennema, Elizabeth, Peterson, Penelope L., Chiang, Chi-Pang., \& Loef, Megan (1989). Using knowledge of children's mathematics thinking in classroom teaching: An experimental study. American Educational Research Journal, 26(4), 499-531.

Case, Robbie (1985). Intellectual development: Birth to adulthood. Orlando, FL: Academic.

Collins, Allan, Brown, John S., \& Newman, Susan E. (1989). Cognitive apprenticeship: Teaching the craft of reading, writing, and mathematics. In L. Resnick (Ed.), Knowing, learning, and instruction: Essay in honor of Robert Glaser (pp. 453-494). Hillsdale, NJ: Erlbaum.

Corno, Lyn, \& Mandinach, Ellen B. (1983). The role of cognitive engagement in classroom learning and motivation. Educational Psychologist, 18, 88-108.

Day, Roger P., Webb, Norman L., Nabate, Molnammed, \& Romberg, Thomas A. (1987). Evaluation of Quantitative Literacy Series: Exploring data and exploring probability. Madison: Wisconsin Center for Educational Research. 
de Lange, Jan, Burrill, Gail, Romberg, Thomas, \& van Reeuwijk, Martin (1993). Learning and testing mathematics in context: The case: Data visualization. Scotts Valley, CA: Wings for Learning.

Demetriou, Andreas (Ed.). (1987). The neo-Piagetian theories of cognitive development: Towards an intcgration [special issuc]. International Journal of Psychology, 22, (5-6), 679728.

Ferguson, George A. (1971). Statistical analysis in psychology and education (3rd ed.). New York: MacGraw-Hill.

Fischbein, Efraim (1975). The intuitive sources of probabilistic thinking in children (C.A. Sherrard, Trans.). Boston: D. Reidel.

Fischbein, Efraim, \& Gazit, Avikam (1984). Does the teaching of probability improve probabilistic intuitions? Educational Studies in Mathematics, 15, 1-24.

Fong, Geoffrey T., Krantz, David H., \& Nisbett, Richard E. (1986). The effects of statistical training on thinking about everyday problems. Cognitive Psychology, 18, 253-292.

Frederiksen, John R., \& Collins, Allan (1989). A systems approach to educational testing. Educational Researcher, 18(9), 27-32.

Gal, Iddo (in press). Statistical tools and statistical literacy: The case of the average. Teaching Statistics.

Garfield, Joan, \& Ahlgren, Andrew (1988). Difficulties in learning basic concepts in probability and statistics: Implications for research. Journal for Research in Mathematics Education, 19(1), 44-63.

Garfield, Joan, \& Ahlgren, Andrew (1994). Student reactions to learning about probability and statistics: Evaluating the quantitative literacy project. School Science and Mathematics, 94(2), 89-95.

Green, David R. (1983). A survey of probability concepts in 3000 pupils aged 11-16 years. In R. Davidson \& J. Swift (Eds.), Proceedings of the First International Conference on Teaching Statistics (pp. 766-783). Sheffield, England: Organising Committee of the First International Conference on Teaching Statistics.

Greeno, James G. (1989). A perspective on thinking. American Psychologist, 44(2), 134-141.

Hancock, Chris, Kaput, James J., \& Goldsmith, Lynn T. (1992). Authentic inquiry with data: Critical barriers to classroom implementation. Educational Psychologist, 27, 337-364.

Hawkins, Anne S., \& Kapadia, Ramesh (1984). Children's conceptions of probability-a psychological and pedagogical review. Educational Studies in Mathematics, 15, 349-377.

Horobin, Karen, \& Acredolo, Curt (1989). The impact of probability judgments on reasoning about multiple possibilities. Child Development, 60, 183-200.

Huff, Darrell (1954). How to lie with statistics. New York: W.W. Norton.

Jacobs, Victoria. R. (1993). Stochastics in middle school: An exploration of students informal knowledge. Unpublished master's thesis, University of Wisconsin, Madison.

Joram, Elana, Resnick, Lauren B., \& Gabriele, Anthony J. (1995). Numeracy as cultural practice: An examination of numbers in magazines for children, teenagers, and adults. Journal for Research in Mathematics Education, 26(4), 346-361.

Kahneman, Daniel, \& Tversky, Amos (1973). On the psychology of prediction. Psychological Review, 80(4), 237-251.

Kahneman, Daniel, \& Tversky, Amos (1982). On the study of statistical intuitions. Cognition, 11(2), 123-141.

Kapadia, Ramesh (1983). A practical approach to statistics. In R. Davidson \& J. Swift (Eds.), Proceedings of the First International Conference on Teaching Statistics (pp. 169-178). Sheffield, England: Organising Committee of the First International Conference on Teaching Statistics.

Konold, Clifford (1989). Informal conceptions of probability. Cognition and Instruction, 6(1), 5998.

Konold, Clifford (1991). Understanding students' beliefs about probability. In E. von Glasersfeld 
(Ed.), Radical Constructivism in mathematics education (pp. 139-156). The Netherlands: Kluwer.

Konold, Clifford, Pollatsek, Alexander, Well, Arnold, Lohmeier, Jill, \& Lipson, Abigail (1993). Inconsistencies in students' reasoning about probability. Journal for Research in Mathematics Education, 24(5), 392-414.

Lajoie, Susanne P., Lavigne, Nancy C., \& Lawless, John (1993, April). The use of hypercard for facilitating assessment: A library of exemplars for reifying statistical concepts. Paper presented at the American Educational Research Association Conference, Atlanta, GA.

Lajoie, Susanne P., Lawless, John, Lavigne, Nancy C., \& Munsie, Steven D. (1993, April). New ways to measure skills of problem solving, reasoning, communication, and connectedness. Paper presented at the annual meeting of the American Educational Research Association, Atlanta, GA.

Lampert, Magdalene L. (1986). Knowing, doing, and teaching multiplication. Cognition and Instruction, 3(4), 305-342.

Lavigne, Nancy C. (1994). Authentic assessment: A library of exemplars for enhancing statistics performance. Unpublished master's thesis, McGill University, Montreal, Quebec, Canada.

Lehrer, Richard, \& Romberg, Thomas A. (in press). Exploring children's data modeling. Cognition and Instruction.

Levin, Iris (1986). Stage and structure: Reopening the debate. Norwood, NJ: Ablex.

Marascuilo, Leonard A., \& Serlin, Ronald C. (1988). Statistical methods for the social and behavioral sciences. New York: W.H. Freeman.

Mosteller, Frederick (1980). Classroom and platform performance. The American Statistician, 34(1), $11-17$.

Mosteller, Frederick (1988). Broadening the scope of statistics and statistical education. The American Statistician, 42(2), 93-99.

National Commission on Excellence in Education (1983). A nation at risk: The imperative for educational reform (Report No. 065-000-00177-2). Washington, DC: U.S. Government Printing Office.

National Council of Teachers of Mathematics Commission on Standards for School Mathematics (1989). Curriculum and evaluation standards for school mathematics. Reston, VA: Author.

National Council of Teachers of Mathematics Commission on Standards for School Mathematics (1991). Professional standards for teaching mathematics. Reston, VA: Author.

National Council for Teachers of Mathematics (1995). Assessment standards for School Mathematics. Reston, VA: Author.

Nisbett, Richard E., Krantz, David H., Jepson, Christopher, \& Kunda, Ziva (1983). The use of statistical heuristics in everyday inductive reasoning. Psychological Revicw, $90(1), 339363$.

Pereira-Mendoza, Lionel, \& Swift, Jim (1981). Why teach statistics and probability-a rationale. In A.P. Shulte \& J.R. Smart (Eds.), Teaching Statistics and Probability Yearbook (pp. 1-7). Reston, VA: National Council of Teachers of Mathematics.

Piaget, Jean, \& Inhelder, Barbel (1975). The origin of the idea of chance in children (L. Leake, Jr., P. Burrell \& H.D. Fishbein, Trans.). New York: W.W. Norton. (Original work published 1951)

Pinard, Adrien, \& Laurendeau, Monique (1969). "Stage" in Piaget's cognitive-developmental theory: Exegesis of a concept. In D. Elkind \& J.H. Flavell (Eds.), Studies in cognitive development (pp. 121-170). New York: Oxford University Press.

Posten, Harry O. (1981). Review of statistical teaching materials for 11-16-year olds. The American Statistician, 35(4), 258-259.

Resnick, Lauren B. (1989). Treating mathematics as an ill-structured discipline. In R.I. Charles \& E.A. Silver (Eds.), The teaching and assessing of mathematical problem solving (pp. 32-60). Reston, VA: National Council of Teachers of Mathematics.

Rogoff, Barbara (1991). Social interaction as apprenticeship in thinking: Guidance and participation 
in spatial planning. In L.B. Resnick, J.M. Levin, \& S.D. Teasley (Eds.), Perspectives on socially shared cognition (pp. 349-364). Washington, DC: American Psychological Association.

Rosebery, Ann S., \& Rubin, Andee (1989). Reasoning under uncertainty: Developing statistical reasoning. Journal of Mathematical Behavior, 8, 205-219.

Russell, Susan Jo, \& Friel, Susan N. (1989). Collecting and analyzing real data in the elementary school classroom. In P.R. Trafton \& A.P. Shulte (Eds.), New directions for elementary school mathematics (pp. 134-148). Reston, VA: National Council of Teachers of Mathematics.

Scheaffer, Richard L. (1988). Statistics in the schools: The past, present and future of the quantitative literacy project. Proceedings of the American Statistical Association from the Section on Statistical Education, 71-78.

Scheaffer, Richard L. (1990). Why data analysis? The Mathematics Teacher, 83(2), 90-93.

Schoenfeld, Alan. H. (1985). Mathematical problem solving. New York: Academic.

Schwartz, Daneil L., Goldman, Susan R., Moore, Allison L., Zech, Linda, Smart, Karen, MayfieldStewart, Cynthia, Vie, Nancy J., \& Barron, Linda (1994, April). Adolescent understanding of sampling in the context of a survey. Paper presented at the annual meeting of the American Educational Research Association, New Orleans, LA.

Shaughnessy, Michael J. (1983). Misconceptions of probability, systematic and otherwise; teaching probability and statistics so as to overcome some misconceptions. In R. Davidson \& J. Swift (Eds.), Proceedings of the First International Conference on Teaching Statistics (pp. 784801). Sheffield, England: Organising Committee of the First International Conference on Teaching Statistics.

Shaughnessy, Michael J. (1992). Research in probability and statistics: Reflections and directions. In D. Grouws (Ed.), Handbook for research in mathematics teaching and learning (pp. 465494). New York: Macmillan.

Singer, Judith D., \& Willett, John B. (1990). Improving the teaching of applied statistics: Putting the data back into data analysis. The American Statistician, 44(3), 223-230.

Tanner, Martin A. (1985). The use of investigations in the introductory statistics course. The American Statistician, 39(4), 306-310.

Tversky, Amos, \& Kahneman, Daniel (1971). Belief in the law of small numbers. Psychological Bulletin, 76(2), 105-110.

Tversky, Amos, \& Kahneman, Daniel (1983). Extensional versus intuitive reasoning: The conjunction fallacy in probability judgment. Psychological Review, 90(4), 293-315.

van Reeuwijk, Martin (1992). The standards applied: Teaching data visualization. The Mathematics Teacher, 85(7), 513-518.

Varga, Tamas (1983). Statistics in the curriculum for everybody: How young children and how their teachers react. In R. Davidson \& J. Swift (Eds.), Proceedings of the First International Conference on Teaching Statistics (pp. 71-80). Sheffield, England: Organising Committee of the First International Conference on Teaching Statistics.

Vygotsky, Lev S. (1978). Mind in Society: The development of higher psychological processes. Cambridge, MA: Harvard University Press.

Watson, Jane M., Collis, Kevin F., \& Moritz, Jonathan B. (1994a). Authentic assessment in statistics using concrete materials. Madison: Wisconsin Center for Educational Research.

Watson, Jane M., Collis, Kevin F., \& Moritz, Jonathan B. (1994b). Authentic assessment in statistics using the media. Madison: Wisconsin Center for Educational Research.

Watts, Donald G. (1991). Why is introductory statistics difficult to learn? And what can we do to make it easier? The American Statistician, 45(4), 290-291.

Webb, Noreen M. (1991). Task-related verbal interaction and mathematics learning in small groups. Journal for Research in Mathematics, 22(5), 366-389. 